\title{
Assédio moral nas instituições de ensino superior: um estudo sobre as condições organizacionais que favorecem sua ocorrência
}

\author{
Moral harassment in higher education institutions: a study of the organizational conditions \\ that favor its occurrence
}

\author{
Míriam Rodrigues ${ }^{1}$ \\ Maria Ester de Freitas ${ }^{2}$
}

\begin{abstract}
Resumo
Este artigo investiga as condições organizacionais que favorecem a ocorrência de assédio moral no ambiente de trabalho, a partir da perspectiva de professores atuantes em cursos de administração de empresas de instituições de ensino superior (IES) privadas na cidade de São Paulo. Foi realizada uma pesquisa qualitativa baseada em dados provenientes de entrevistas e análise documental, submetidos à análise de conteúdo. Os resultados evidenciaram que 0 assédio moral é motivado tanto por questões de ordem pessoal, quanto por questões organizacionais e que tem como elementos deflagradores o posicionamento das IES privadas no cenário competitivo em que estão inseridas e a fragilidade ou inexistência de normas e processos referentes à prevenção e ao tratamento de casos de assédio moral. Os resultados evidenciaram que o assédio moral é motivado tanto por questões de ordem pessoal, quanto organizacionais, tendo como elementos deflagradores o posicionamento das IES privadas no cenário competitivo em que estão inseridas e a fragilidade ou inexistência de normas e processos referentes à prevenção e ao tratamento do problema.
\end{abstract}

Palavras-chaves: Assédio moral. Instituições de ensino superior. Condições organizacionais.

This study investigates the organizational conditions that promote the occurrence of moral harassment in the workplace, from the perspective of professors working on private courses in Business Administration Higher Education Institutions (HEIs) in the city of São Paulo. It was performed a qualitative research based on data from interviews and document analysis, which were submitted to content analysis. The results showed that moral harassment is motivated both by personal issues, as by organizational issues, and its elements responsible for triggering it is the placement of private HEls in the competitive landscape in which they operate and the weakness or absence of standards and processes concerning the prevention and treatment of cases of moral harassment.

Keywords: Moral harassment. Higher education institutions. Organizational conditions.

Artigo submetido em 23 de abril de 2013 e aceito em 10 de fevereiro de 2014.

DOI: http://dx.doi.org/10.1590/1679-39518275

1 Professora assistente doutora da Universidade Presbiteriana Mackenzie - UPM; Doutora pela Fundação Getulio Vargas/EASP. Endereço UPM: Rua da Consolação, 896, CEP 01302-907, São Paulo - SP, Brasil. E-mail: miriam.rodrigues@mackenzie.br

2 Professora titular da FGV/EAESP; Doutora pela Fundação Getulio Vargas/EAESP. Endereço: EAESP - Av. Nove de Julho, 2029, CEP 01313-902, São Paulo - SP, Brasil. E-mail: ester.freitas@fgv.br 


\section{Introdução}

Esta pesquisa teve como objetivo identificar e analisar as práticas de assédio moral no ambiente acadêmico, bem como as condições organizacionais que favorecem a ocorrência desse fenômeno, a partir da percepção dos docentes atuantes em instituições de ensino superior privadas, na cidade de São Paulo.

Para Zaluar e Leal (2001), a violência que ocorre no ambiente escolar possui duas dimensões: a primeira, representada pela violência física e a segunda, representada por palavras ou atos que negam, oprimem ou destroem psicologicamente o outro. Dessa forma, embora a violência física tenha uma materialidade incontestável, é importante atentar para a dimensão moral das agressões que ocorrem entre os muros da escola e em seu caráter essencialmente simbólico e imaterial, bem como para o fato de que as práticas violentas no ambiente escolar não estão circunscritas às regiões precárias ou escolas públicas, atingindo também as escolas particulares em áreas privilegiadas (OLIVEIRA, 2008; SPOSITO, 2001).

Ao abordar o assédio moral como a violência perversa no cotidiano, Hirigoyen (2002a) traz à luz a análise de situações que aparentemente podem ser consideradas inofensivas - alusões, sugestões ou não ditos -, mas que podem efetivamente desequilibrar uma pessoa, sem que os que a rodeiam intervenham. As formas de assédio moral no mundo do trabalho, nas universidades ou instituições escolares são mais estereotipadas que na vida privada, mas nem por isso menos destrutivas, sendo o meio educativo, de acordo com essa autora francesa, um dos mais afetados pelas práticas de assédio moral.

Os primeiros estudos sobre a violência escolar foram realizados nos EUA na década de 1950. Ao longo do tempo, a análise desse fenômeno no ambiente escolar indica que suas proporções e gravidade têm aumentado. Inicialmente, a violência na escola era tratada como uma simples questão de disciplina, cujas análises recaíam sobre a violência do sistema escolar, principalmente, por parte dos professores contra os alunos, representada pelas punições e castigos corporais. Posteriormente, encontram-se na literatura contemporânea, sociólogos, antropólogos, psicólogos e outros especialistas privilegiando a análise da violência praticada entre alunos ou de alunos contra a propriedade, representada por atos de vandalismo e de depredação; sendo, em menor proporção, estudada a violência na relação entre alunos e professores e viceversa (ABRAMOVAY e RUA, 2002).

Ataques, inclusive físicos, aos professores ou insultos que lhes são dirigidos não constituem ocorrências raras, representando a perda de limites morais ou religiosos que constituíam uma espécie de código de civilidade, de forma que somente quando os fatos aparecem na cena pública, registrados e ampliados pela mídia, é que a indignação encontra seu lugar (CHARLOT, 2002; HIRIGOYEN, 2002a). Ao abordar as diversas formas de violência no ambiente escolar, Sposito (2001) ressalta que existe a necessidade de que sejam investigados processos mais amplos, relacionados à expansão das instituições de ensino superior nos últimos anos.

No que se refere à educação superior, foco deste estudo, Minto (2006) observa que esta constitui parte indissociável do complexo de relações sociais e expressa igualmente seus antagonismos. Subordinado ao imediatismo de uma economia globalizada, o ensino superior tem sido referenciado com a utilização de termos depreciativos, como sucateamento, mercantilização, desconstrução, precarização e empresariamento, dentre outros. Esses termos indicam a direção nefasta que tem sido percebida por estudantes, docentes e sindicatos, uma vez que a centralidade da educação está cada vez mais vinculada às virtudes e vícios do mercado, nos quais incluem-se a lógica de expansão e de acumulação (MINTO, 2006).

Docentes que atuam em escolas particulares têm enfrentado situações difíceis em razão da natureza empresarial que reside nesses estabelecimentos de ensino. Ainda que as escolas veiculem um discurso que enaltece seus atributos pedagógicos, frequentemente, este aspecto apresenta contradições, a partir da necessária e obsessiva preocupação com os lucros. Isso pode resvalar em questões que envolvem o ambiente de trabalho dessas instituições,_afetando o relacionamento dos docentes com gestores, alunos e o próprio exercício de seu trabalho, criando assim um ambiente propício ao assédio moral. 


\section{Referencial Teórico}

Apesar dos discursos que proclamam elementos como a humanização e democratização no mundo do trabalho, empowerment e participação de todos os níveis nos processos decisórios, é sabido que, muitas vezes, empresas desenvolvem práticas abusivas quanto à centralização do poder. O entendimento de que as sociedades modernas sofrem com um alto nível de desemprego e uma competitividade acirrada pode ajudar a compreender os fatores que favorecem as práticas de assédio, pois, diante desse cenário, muitos profissionais acabam se sujeitando a situações constrangedores e indesejáveis no ambiente de trabalho por temerem perder o emprego (FREITAS, 2001). Conquanto no Brasil de hoje vivamos uma fase particularmente promissora em relação ao emprego, não podemos esquecer que o nível de competição entre negócios vem crescendo de forma vertiginosa, como também é cada vez mais feroz a competição no mercado profissional.

A luta pela sobrevivência por parte das organizações e a busca pela ampliação de espaço no mercado trouxe consequências para todos: precariedade do emprego, flexibilização das relações de trabalho, interesse em reduzir os custos de trabalho, crescimento do desemprego, terceirização, crescimento do setor informal e a tendência à contratação por tempo determinado, dentre outras. Nesse cenário de incertezas - em alguns casos, utilizando as práticas do "vale tudo" e/ou do "cada um por si" -, empresas e trabalhadores estão imersos em ambientes altamente propícios ao aparecimento das mais diferentes formas de violência no trabalho. Estas podem representar a manifestação de uma violência ainda maior, que encontra seus fundamentos em uma sociedade que vê na economia a resposta para todos seus problemas e em uma organização do trabalho cada vez menos comprometida com o ser humano (FREITAS, HELOANI e BARRETO, 2008).

Entre as diferentes formas pelas quais a violência pode apresentar-se no ambiente de trabalho, o assédio moral configura-se como uma forma de violência que nem sempre é explícita, ocorrendo em alguns casos de forma sutil e indireta, mas com efeitos que podem ser devastadores, capazes de afetar não somente o trabalhador, mas também a própria empresa e seu entorno. Heloani (2008) observa que o assédio moral constitui um subproduto de uma arena competitiva global, sendo fundamental compreender e considerar esse contexto, uma vez que todas as práticas e políticas de prevenção e combate ao problema serão insuficientes se as condições e a filosofia de negócios, que conduzem à hipercompetitividade, não mudarem.

Os estudos sobre o assédio moral tiveram sua origem na academia. Foi o interesse da própria sociedade e de instâncias diversas, como a mídia, sindicatos e justiça, que abriram espaço para que as discussões sobre esse fenômeno ganhassem amplitude.

Em 1976, o psiquiatra americano Carroll Brodsky publicou um estudo pioneiro denominado The harassed worker, em que relata uma pesquisa realizada com pessoas que alegavam maus tratos no ambiente de trabalho. Entretanto, foi a partir das pesquisas e das publicações da psiquiatra e psicoterapeuta familiar francesa Marie France Hirigoyen e do alemão Heinz Leymann, que o tema começou a ganhar notoriedade.

No início dos anos 1980, inspirado em sua experiência como terapeuta familiar, Leymann começou a investigar o sofrimento no trabalho, chegando a inéditos e preocupantes resultados, que rapidamente foram divulgados no ambiente acadêmico e, posteriormente, em outras instâncias, a partir da publicação, em 1986, de seu livro Mobbing: psychological violence at work. O aspecto essencial das pesquisas conduzidas por Leymann e sua equipe estava relacionado à apreensão do problema e de termos que não sugerissem ambiguidade para os objetos de estudo e comportamentos dos pesquisados (EINARSEN, HOEL, ZAPF et al., 2011).

O debate sobre as questões referentes ao assédio moral ganhou evidência em escolas, universidades, sindicatos e empresas, entre outros locais / espaços, a partir de 1998, com a publicação do livro $L e$ harcèlement moral: la violence perverse au quotidien (traduzido para o português como Assédio moral: a violência perversa no cotidiano), escrito por Hirigoyen. 
Ao caracterizar o processo de assédio, Hirigoyen (2002a) destaca que um ato inofensivo ou ainda imperceptível pode identificá-lo, e que esse fenômeno pode estar presente tanto na vida doméstica como na esfera profissional, existindo em toda parte e sendo analisado a partir de diferentes enfoques, conforme o contexto e a cultura nos quais está inserido.

A definição do que seja assédio moral e quais são seus limites não é consensual, uma vez que se trata de um campo ainda em construção. Bradaschia (2007) realizou um amplo estudo bibliográfico com o objetivo de sistematizar as informações referentes ao assédio moral. Sobre esse aspecto, afirma que as definições variam conforme a frequência e a duração da situação de assédio e dos atos passíveis de serem considerados ou não como assédio moral. Por outro lado, a autora sinaliza consenso na literatura acadêmica, no sentido de que o assédio moral envolve um tratamento perverso por parte de um ou mais indivíduos no ambiente de trabalho e que a repetição é uma característica fundamental do fenômeno.

Soares (2012) observa que o assédio moral constitui um processo multicausal com diferentes abordagens e análises focalizadas no indivíduo, no contexto ou em ambos. Já, Glina e Soboll (2012) chamam atenção para o fato de que existem inúmeras definições sobre o assédio moral no trabalho, cada uma enfatizando determinados aspectos. Para essas autoras, o assédio moral no ambiente de trabalho refere-se a um padrão relacional entre as pessoas no contexto de trabalho.

Neste estudo, dentre as diferentes definições existentes na literatura especializada, optou-se pela definição de assédio moral apresentada por Freitas, Heloani e Barreto (2008), por esta apresentar elementos referentes à frequência, persistência e repetição dos comportamentos abusivos que são consensuais na literatura acadêmica sobre assédio moral (BRADASCHIA, 2007; MEURER e STREY, 2012). Dessa forma, assédio moral é:

\begin{abstract}
uma conduta abusiva e intencional, frequente e repetida, que ocorre no ambiente de trabalho e que visa a diminuir, a humilhar, a vexar, a constranger, a desqualificar e a demolir psiquicamente um indivíduo ou um grupo, degradando as suas condições de trabalho, atingindo a sua dignidade e colocando em risco a sua integridade pessoal e profissional. (FREITAS, HELOANI e BARRETO, 2008, p. 37)
\end{abstract}

Apesar do necessário cuidado na definição do fenômeno, é possível identificar uma tendência de generalização, de forma que, muitas vezes, são nomeadas como assédio moral algumas outras situações desagradáveis no trabalho ou que apresentem repercussões na saúde física ou mental dos trabalhadores. Episódios pontuais, pressão para a produtividade, exigências de submissão às regras da empresa ou metas exageradas podem ser confundidos com situações de assédio moral. Birman (2005) e Soboll (2008) também chamam atenção para a notoriedade pública do assédio moral, que pode estar sendo desmesuradamente inflacionada no imaginário contemporâneo, reforçando a adoção de definições imprecisas e assim tornando o sentido do fenômeno evanescente e sem fronteiras bem traçadas.

Cassitto, Fattorini, Gilioli et al. (2012) utilizam um quadro explicativo para sinalizar os principais aspectos que diferenciam os conflitos saudáveis das situações de assédio moral. Destacam que o que diferencia o assédio moral dos demais conflitos no mundo do trabalho é que o assédio moral segue um padrão relacional confuso e que os comportamentos são antiéticos, as regras não são claras, há parcialidade nos julgamentos e avaliações, a comunicação é indireta e evasiva, além das divergências serem encobertas ou dissimuladas. Já no caso das situações de conflitos, embora possam existir eventuais desconfortos típicos desse tipo de situação, não são observados os elementos mencionados que ocorrem nas situações de assédio moral. 


\section{Quadro 1}

Diferenças entre conflitos saudáveis e situações de assédio moral

\begin{tabular}{|l|l|}
\hline \multicolumn{1}{|c|}{ Conflitos saudáveis } & \multicolumn{1}{c|}{ Assédio moral } \\
\hline Regras e tarefas claras & Regras ambíguas \\
\hline Relações em que há colaboração & Comportamento sem colaboração/boicote \\
\hline Objetivos comuns e compartilhados & Falta de previsão \\
\hline Organização saudável & Relações interpessoais ambíguas \\
\hline Conflitos e confrontos ocasionais & Ações sem ética e de larga duração \\
\hline Estratégias abertas e francas & Estratégias equivocadas \\
\hline Conflitos e discussões abertas & Ações encobertas e negação de conflito \\
\hline Comunicação sincera e honesta & Comunicação indireta e evasiva \\
\hline
\end{tabular}

Fonte: Cassitto, Fattorini, Gilioli et al. (2012, p. 15).

Ainda no que se refere às diferenças entre os conflitos organizacionais e as situações de assédio moral, Freitas, Heloani e Barreto (2008) ressaltam que os conflitos geralmente fazem emergir as divergências e as discórdias, o que possibilita sua negociação ou resolução. Contudo, nos casos de assédio não há necessariamente um conflito entre o agressor e a vítima, sendo possível que a vítima ignore o problema ou que o considere insignificante, podendo até confundi-lo com uma brincadeira de mau gosto. Nesses casos, somente num segundo momento, após ser regularmente acuada ou atacada, é que a vítima percebe a multiplicação dos ataques e seu estado de inferioridade ou fragilidade, o que dificulta qualquer esboço de reação.

Muito embora possa ser praticado em qualquer lugar, de acordo com as condições e circunstâncias de cada organização, Hirigoyen (2002b) destaca que existem locais de trabalhos mais expostos. Ainda de acordo com sua pesquisa, o assédio predomina no setor terciário, no setor de medicina e no de ensino; ou seja, setores nos quais as tarefas não são definidas com muita objetividade, em que sempre é possível culpar alguém por alguma coisa.

Bradaschia (2007) observa que existem muitas variações no que se refere aos setores nos quais os casos de assédio moral ocorrem com mais frequência. Ainda que os resultados variem muito conforme o país e a pesquisa, tendências foram identificadas nos estudos analisados por essa autora, indicando que os funcionários públicos possuem um risco maior de sofrer assédio moral, assim como os setores em que o exercício profissional envolve maior frequência de relações interpessoais, corroborando as pesquisas de Hirigoyen (2002b) e de Einarsen, Hoel, Zapf et al. (2011).

No que se refere ao meio educativo, Hirigoyen (2002b) reconhece que esse setor é um dos mais afetados pelas práticas de assédio moral, muito embora os estudos destaquem a violência sofrida pelos alunos e, em menor proporção, a violência sofrida pelos profissionais que atuam nesse segmento. No caso do professor, a autora explica que o fato de suas atividades não poderem ser inteiramente codificadas poderá facilitar sua estigmatizarão no relacionamento com os alunos e que as práticas de assédio no meio educativo são banalizadas. Considerando que os professores que atuam no nível superior, além da docência, também podem exercer atividades relacionadas à pesquisa, Hirigoyen (2002b) destaca que a busca pela notoriedade 
pode levar os pesquisadores a lutas ferozes ou ainda a rivalidades, bem como à adoção de práticas ilícitas para alcançar seu "lugar ao sol". Assim, um pesquisador poderá se apropriar dos conhecimentos ou ideias de outros, podendo copiar escritos ou utilizar palavras que não são suas, buscando estar sempre à frente de seus colegas no que se refere à quantidade de publicações, em detrimento dos progressos científicos. Também podem ocorrer situações em que chefes de departamentos se sintam inseguros por causa do brilhantismo de algum pesquisador e, com isso, "lancem mão" de diversas táticas perversas para impedir o trabalho deste (HIRIGOYEN, 2002b).

Além desses aspectos, deve-se também considerar que as práticas de assédio moral no âmbito educacional poderão ser consideradas traços perversos comuns em determinados ambientes, podendo ser sustentadas pela cultura da instituição e constituir uma fonte de violência induzida, como esclarece Sirota (2008).

No que se refere aos cursos superiores de administração de empresas, Paula e Rodrigues (2006) observam que a qualidade desses cursos tem sofrido reflexos diretos de sua rápida expansão. Estes autores também abordam o fato de que o ensino de administração tornou-se um grande negócio e que muitas instituições de ensino, notadamente as particulares, oscilam entre uma lógica imobiliária, relacionada à ampliação e embelezamento de suas instalações físicas, e uma lógica hoteleira, relacionada à plena ocupação das salas de aula, independentemente da qualidade de seus hóspedes.

O trabalho desenvolvido pelo docente é diretamente influenciado pelo ambiente altamente competitivo no qual as IES privadas se encontra. Isso inclui as demandas quantitativas e financeiras da instituição para que se mantenha/aumenta a quantidade de alunos, bem como as exigências do mercado referentes à qualidade do trabalho desenvolvido no interior das instituições e sua imagem, a qual, por sua vez, é balizada principalmente pelos resultados de suas avaliações. Nesse contexto, o próprio clima de trabalho nas IES tem se modificado, com impactos diretos nas relações humanas verificadas no interior dessas instituições, na medida em que as prioridades são fixadas pelo ambiente externo, que valoriza o trabalho focado no domínio acadêmico performático em detrimento da formação e dos aspectos socioeducativos (LELIS, 2012).

Pita (2010) afirma que o assédio moral e as retaliações poderão figurar entre as consequências sofridas por aqueles que resistem às múltiplas exigências das instituições de ensino, exigências estas que incluem aspectos relacionados à contabilização de sua produtividade. Como nas plantas industriais toyotistas, no ensino superior as metas estipuladas são elevadas, não importando a forma como serão alcançadas. Além disso, a flexibilidade, a mobilidade e a agilidade é que modelam o trabalho, sendo o professor responsabilizado diretamente pelo sucesso ou fracasso da empresa, de acordo com os resultados numéricos.

Uma vez que o assédio moral é um fenômeno amplo e complexo, seus impactos podem ser profundos na vida do trabalhador, gerando inúmeras consequências, cuja abrangência vai além da relação entre aquele que assedia e quem é assediado, podendo assumir contornos maiores e afetando também a empresa e a sociedade como um todo.

Freitas (2007) destaca que no nível individual é a vida psicossocial do indivíduo que será diretamente atingida pelo assédio, o que poderá envolver elementos relacionados à personalidade, à identidade e à autoestima. Como consequência disso, podem ocorrer impactos sua vida psíquica, social, profissional, familiar e afetiva, atingindo sua saúde, reduzindo sua capacidade de concentração, induzindo ao erro e colocando em risco seu emprego e, até mesmo, sua vida. No nível organizacional, os efeitos das ações de assédio moral podem ser identificados pelo afastamento de profissionais por doenças e acidentes de trabalho e pela elevação dos índices de absenteísmo e de rotatividade de pessoal. As consequências disso poderão envolver custos de reposição, perda de equipamentos (como resultado da desconcentração dos trabalhadores), queda de produtividade (em função da moral do grupo e do clima organizacional), custos judiciais decorrentes de indenizações trabalhistas, custos de imagem, desmotivação interna, redução da atratividade de talentos e eventual redução do valor da marca. Praticamente ignorado, o âmbito social também deve ser considerado, pois "existem preços pagos por todos numa sociedade quando indivíduos são massacrados pelas práticas de assédio" (FREITAS, 2007, p. 6). 
Dessa forma, a incapacitação precoce de profissionais causada por acidentes de trabalho, o aumento das despesas médicas e com benefícios previdenciários, a elevação dos índices de suicídios na sociedade, a desestruturação familiar e social das vítimas, a perda do investimento social em educação e formação profissional, bem como o custo do potencial produtivo dos profissionais afastados por invalidez ou, ainda, a redução de seu potencial empregatício requerem atenção como possíveis consequências do assédio moral no ambiente organizacional.

Ainda sobre essa temática, Freitas (2007) destaca que, toda vez que um profissional capaz é tornado incapaz, a sociedade toda paga a conta, observando ainda que, além das questões de natureza médica e trabalhista, existem outras relacionadas aos custos dos processos judiciais e à própria sobrecarga do sistema judiciário. A autora também observa que deve ser levado em conta que o custo econômico de ações indenizatórias será repassado aos preços, que poderão ser cobrados de forma indiscriminada aos consumidores dessa organização.

O assédio moral gera também um clima de inquietação, medo e fragilidade que se estende à sociedade como um todo, uma vez que o fenômeno da globalização, as constantes reestruturações e as fusões de empresas podem levar as pessoas a perderem a confiança em si mesmas e a adotarem uma postura de descrédito com relação ao mundo do trabalho (HIRIGOYEN, 2002b).

O assédio moral é, pois, um fenômeno devastador na vida de um indivíduo, de uma empresa e de uma sociedade; portanto, diz respeito a todos. Se profissionais e organizações fecharem os olhos diante dessa questão, estarão reforçando um comportamento que fere o direito que todos têm de serem tratados e respeitados como seres humanos. Assim, o assédio moral vai além de uma questão moral, constituindo uma questão econômica e também um crime, que deve ser punido exemplarmente (FREITAS, HELOANI e BARRETO, 2008).

Uma prevenção eficiente do assédio moral é a maneira mais eficaz de tratar essa questão. Quando um empregado é maltratado, a empresa pode estar desperdiçando talentos, ao passo que quando é construído um ambiente de respeito, é possível atrair e tornar fiéis os melhores empregados. Além disso, outra motivação para que as empresas atuem de modo mais objetivo com relação ao assédio moral é o zelo por sua imagem, evitando repercussões negativas na mídia e, consequentemente, um retorno negativo aos acionistas (HIRIGOYEN, 2002b). A autora lembra, ainda, que é preciso haver vontade real de mudança por parte das empresas e também dos trabalhadores. Ela acrescenta que deve ser considerado um fator de sorte para uma empresa quando seus empregados reagem, pois isto lhes dá a oportunidade de mudar seus métodos de administração e melhorar a comunicação dentro da organização.

\section{Procedimentos Metodológicos}

Realizou-se uma pesquisa de natureza qualitativa, orientada pelo paradigma interpretativo (SCHWANDT, 2006), em que se buscou entender as relações entre os diferentes atores e as reconstruções e reinterpretações que esses atores fizeram de suas experiências consideradas situações de assédio moral.

Quanto aos procedimentos adotados na pesquisa empírica, foram analisados dados apresentados em seis processos trabalhistas, disponibilizados pelo Sindicato dos Professores de São Paulo (Sinpro-SP), referentes a queixas efetuadas por profissionais quanto a situações percebidas como assédio moral. Também foram analisadas 17 entrevistas em profundidade, baseadas em roteiro preestabelecido, com professores atuantes em cursos da área de administração de empresas de IES particulares da cidade de São Paulo, que foram gravadas e transcritas na íntegra para posterior análise. $\mathrm{O}$ acesso aos entrevistados deu-se a partir das redes sociais e profissionais dos pesquisadores (VALLES, 1997; SIERRA, 1998), bem como a partir de indicações feitas pelos profissionais entrevistados. O critério de saturação (BAUER e AARTS, 2002; PIRES, 2010; VALLES, 1997) foi utilizado para definir o encerramento do processo de realização das entrevistas. 
A utilização de mais de uma fonte de dados refletiu a tentativa de buscar elementos que permitissem a análise em profundidade do fenômeno a ser estudado (DENZIN e LINCOLN, 2006). No caso desta pesquisa, entendeu-se que a complexidade do objeto e as suas múltiplas influências demandaram a conjugação desses dois instrumentos.

Deve ser destacado que a opção pela coleta e análise de dados provenientes de docentes atuantes em cursos superiores de administração de empresas (graduação e/ou pós-graduação) em IES do setor privado justificase pela representatividade das IES privadas e dos cursos de administração de empresas, tanto no Brasil como na cidade de São Paulo.

Considerando a natureza desta pesquisa, os dados obtidos a partir da análise documental e das entrevistas foram tratados mediante análise de conteúdo. Nesse sentido, Godoy (1995, p. 23) destaca que "qualquer comunicação que veicule um conjunto de significações de um emissor para um receptor pode, em princípio, ser decifrada pelas técnicas de análise de conteúdo". Por trás de um discurso aparente, simbólico e polissêmico, esconde-se um sentido que deve ser desvendado, complementa a autora.

De acordo com Franco (2008), o ponto de partida da análise de conteúdo é a mensagem, seja esta verbal, gestual, silenciosa, figurativa ou documental.

As mensagens expressam as representações sociais na qualidade de elaborações mentais construídas socialmente, a partir da dinâmica que se estabelece entre a atividade psíquica do sujeito e o objeto do conhecimento. Relação que se dá na prática social e que se generaliza via linguagem. Sendo constituídas por processos sociocognitivos, têm implicações na vida cotidiana, influenciando não apenas e comunicação e a expressão das mensagens, mas também os comportamentos. (FRANCO, 2008, p. 12)

A análise de conteúdo dos processos trabalhistas e relatos obtidos mediante a realização das entrevistas foi realizada de acordo com as três fases propostas por Bardin (2006): a pré-análise, a exploração do material e o tratamento dos resultados.

Na pré-análise, foi realizado o primeiro contato com o material coletado, denominado por Bardin (2006) de leitura flutuante. Na fase subsequente, exploração do material, deu-se o procedimento de categorização dos dados. Nesse processo, inicialmente as respostas foram classificadas em categorias de menor amplitude e, posteriormente, em categorias mais amplas, relacionadas às vivências de assédio moral narradas pelos docentes e ao contexto organizacional onde essas práticas ocorreram. Destaca-se que na organização dos dados resultantes das entrevistas foi utilizado o software NVivo9 como apoio para esse processo. No caso dos processos disponibilizados pelo Sinpro-SP, não foi possível a utilização do NVivo, uma vez que os processos não estavam digitalizados. Nesse caso, a análise do material ocorreu sem a utilização do software.

No processo de organização e categorização dos dados, foram consideradas as temáticas abordadas nas falas dos entrevistados e as informações apresentadas nos processos trabalhistas. Isso gerou várias leituras do material coletado e, principalmente, das categorias que foram sendo estruturadas, no sentido de que as temáticas agrupadas pudessem tornar-se elementos efetivamente constitutivos de um conjunto, conforme proposto por Bardin (2006). Dessa forma, as categorias emergiram paulatinamente, como resultado do processo de leitura, agrupamento e reagrupamento dos dados.

É importante observar que os requisitos de exclusão mútua, pertinência, objetividade, fidedignidade e produtividade (BARDIN, 2006; FRANCO, 2008) foram utilizados no sentido de obter um conjunto de categorias que propiciasse uma adequada análise do fenômeno do assédio moral a partir dos dados coletados. Destaca-se que o critério de categorização utilizado foi o semântico, e que o processo adotado para a categorização foi o procedimento por "milha", que consiste na classificação progressiva e analógica dos elementos, à medida que foram identificados pelo pesquisador (BARDIN, 2006). 
Foram 28 as categorias temáticas identificadas inicialmente (categorias primárias), agrupadas em cinco categorias secundárias e três categorias terminais, conforme quadro 2.

\section{Quadro 2}

\section{Categorias temáticas depreendidas a partir da análise dos dados}

\begin{tabular}{|c|c|c|}
\hline Categorias primárias & Categorias secundárias & Categorias terminais \\
\hline $\begin{array}{l}\text { - } \text { Como ocorrem práticas de assédio } \\
\text { - } \text { Motivos da ocorrência de assédio } \\
\text { - } \text { - Quando ocorreu a situação } \\
\text { - Quanto tempo durou }\end{array}$ & $\begin{array}{l}\text { Onde, como e por que ocorreram } \\
\text { as práticas de assédio moral }\end{array}$ & Práticas de assédio moral \\
\hline $\begin{array}{l}\text { - Quem são os assediadores } \\
\text { - } \text { Quem são as vítimas } \\
\text { - } \text { Impacto do assédio na vida } \\
\text { - Impacto na carreira docente } \\
\text { - Encaminhamento das denúncias } \\
\text { - Como reagiu ao assédio } \\
\text { - Impactos no ambiente de trabalho } \\
\text { - O que sentiu }\end{array}$ & $\begin{array}{l}\text { Vítimas } \\
\text { Assediadores }\end{array}$ & $\begin{array}{l}\text { Protagonistas e seus } \\
\text { comportamentos }\end{array}$ \\
\hline 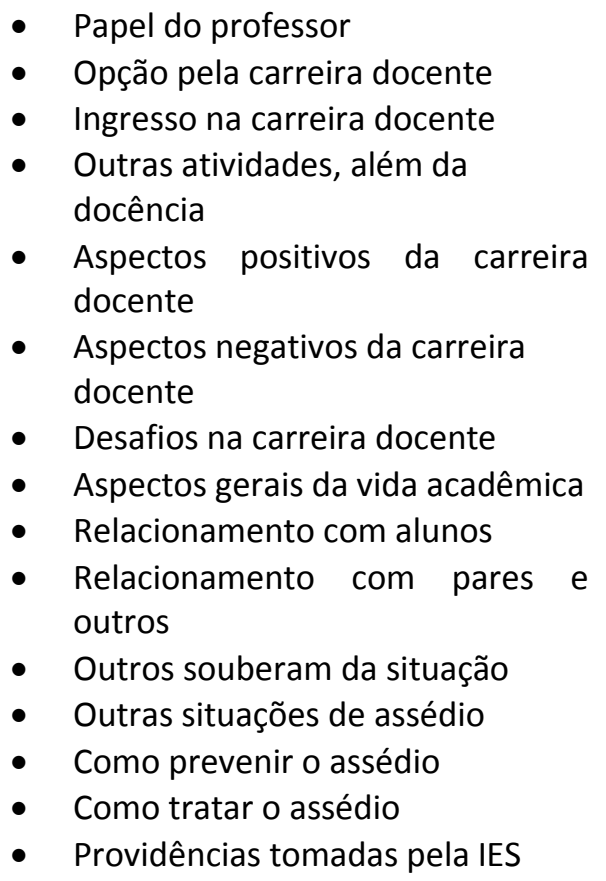 & $\begin{array}{l}\text { O ambiente acadêmico percebido } \\
\text { pelo docente } \\
\text { Prevenção, combate e } \\
\text { tratamento do assédio moral no } \\
\text { ambiente acadêmico }\end{array}$ & $\begin{array}{l}\text { Contexto organizacional e } \\
\text { trabalho }\end{array}$ \\
\hline
\end{tabular}

Fonte: Elaborado pelos autores a partir dos dados da pesquisa.

Como aporta Minayo (2010), todo o processo de organização e tratamento do material coletado teve como objetivo identificar uma lógica peculiar e interna das informações analisadas, sendo esta a contribuição singular e contextualizada deste estudo, que será apresentada na sequência. 


\section{Análise dos Resultados}

Tanto as situações observadas nos processos trabalhistas quanto aquelas narradas pelos professores entrevistados abordam situações relacionadas à desqualificação, constrangimentos e desrespeitos das mais diversas naturezas, afetando a saúde física e/ou psíquica do docente, seu bem-estar pessoal e profissional.

Cumpre destacar que nem todas as situações analisadas foram caracterizadas como assédio moral, em conformidade com o conceito de assédio moral adotado neste estudo. A análise dos dados dos seis processos trabalhistas disponibilizados pelo Sinpro-SP (quadro 2), apesar de não apresentarem elementos suficientes para caracterizá-los ou não como assédio moral, trouxe à tona muitas mazelas, dissabores e inúmeras situações indignas e de desrespeito vivenciadas por professores atuantes em cursos de administração de empresas em IES privadas. Isso contribuiu para o entendimento de alguns aspectos pertinentes à relação estabelecida entre as IES e seu corpo docente, principalmente, no que se refere ao momento do desligamento dos profissionais.

Além do eventual prejuízo moral e/ou financeiro sofrido pelo docente, em todos os casos foi possível evidenciar o esforço das IES para evitar perda financeira - mesmo que isso envolvesse direitos trabalhistas na rescisão dos contratos de trabalho. Isto é, em todos os processos analisados, foi possível identificar que a IES deixou de pagar ao docente algum ou vários de seus direitos trabalhistas. Em cinco deles não foi possível observar a configuração de processos perversos, mas de atos perversos isolados. Apenas em P6 (quadro 3), a exposição dos fatos sinalizou a possibilidade de um processo de assédio moral sofrido pelo docente.

Quadro 3

Sinopse de processos trabalhistas disponibilizados pelo Sinpro-SP

\begin{tabular}{|c|l|}
\hline \multicolumn{2}{|c|}{ Situação } \\
\hline P1 & Demissão por justa causa por perseguição política \\
\hline P2 & Demissão com falseamento de dados na carteira profissional \\
\hline P3 & Demissão por justa causa por participação em movimento grevista \\
\hline P4 & Demissão por telegrama sem recebimento das verbas rescisórias \\
\hline P5 & Demissão por justa causa para fugir ao pagamento das verbas rescisórias \\
\hline P6 & Redução da remuneração, desqualificação do trabalho do professor \\
\hline
\end{tabular}

Fonte: Dados da pesquisa, 2012.

Os dados que emergiram da análise das entrevistas demonstraram a dificuldade que aqueles que declararam terem sido assediados têm para identificar e entender o que é o que não é assédio moral, corroborando a visão de Barreto (2005); Caran (2007); Freitas (2007a); Freitas, Heloani e Barreto (2008); Sesso (2005); Soboll (2008) e Hirigoyen (2002b). Nesse sentido, tal dificuldade apenas reforça a percepção de quão delicado é o assunto, bem como da necessidade de uma definição conceitual que permita classificar como assédio moral ou não uma determinada ocorrência.

Das 22 diferentes situações relatadas pelos 17 entrevistados, nota-se que em alguns casos um entrevistado abordou mais de uma situação, cinco delas não configurando assédio moral (quadro 4). Em conformidade com elementos observados no aporte teórico (FREITAS, HELOANI e BARRETO, 2008; HIRIGOYEN, 2002b; SOBOLL, 2008), as situações 1, 2, 3 e 4 não podem ser caracterizadas como assédio moral por não 
contemplarem elementos pertinentes à repetição ou à frequência de ocorrências, apresentando-se como eventos pontuais. Já na situação 5, apesar de ter ocorrido mais de uma vez, também não há a caracterização de um processo de assédio moral, por não apresentar, conforme relato do entrevistado, elementos pertinentes à intenção de prejudicar ou ainda a degradação das condições de trabalho e/ou aspecto referente que possa ser visto como comportamento hostil.

Quadro 4

\section{Situações não caracterizadas como assédio moral}

\begin{tabular}{|c|l|}
\hline $\mathbf{1}$ & Promessa de remuneração por determinado trabalho que não foi cumprida. \\
\hline $\mathbf{2}$ & Aluna confundiu amizade com possibilidade de relacionamento amoroso. \\
\hline $\mathbf{3}$ & Professor foi demitido por telegrama. \\
\hline $\mathbf{4}$ & Aluno tentou agredir fisicamente o professor. \\
\hline $\mathbf{5}$ & Professor recebia advertências de sua liderança hierárquica por questões políticas \\
\hline
\end{tabular}

Fonte: Dados da pesquisa, 2012.

É necessário ressaltar que, embora não constituam situações de assédio moral, as situações vivenciadas pelos docentes nos casos anteriormente apontados não são questões corriqueiras ou sem importância. Por isso não devem ser ignoradas ou banalizadas. A não atribuição da devida importância em situações como estas, que demandam tratamento e administração em suas causas e consequências, poderá gerar impactos negativos para todos os envolvidos, sejam os próprios docentes, os alunos e a instituição. Além disso, observa-se que, quando não são tomadas atitudes diante de situações tão indesejáveis como as descritas, corre-se o risco de que estas sejam tidas como naturais; ou seja, entendidas como algo que faz parte da cultura e do ambiente de trabalho dessas IES, Assim, seus impactos negativos são potencializados e esses ambientes organizacionais são cada vez mais distanciados de relacionamentos humanos dignos e respeitosos, bem como das inúmeras consequências positivas que estes também proporcionam a todos os envolvidos.

As situações caracterizadas como assédio moral e os respectivos assediadores apontados pelos docentes entrevistados são apresentados de maneira sumarizada no quadro 5. No que se refere à relação entre alunos e professores, os casos de assédio analisados indicam uma inversão de papéis quanto a quem detém o poder nos ambientes onde o aluno é considerado e tratado como cliente pela IES. Esse "empoderamento" do aluno pôde ser observado em situações nas quais não somente a autoridade, mas a própria ação pedagógica docente foi desconsiderada, desqualificada ou preterida, devido ao entendimento por parte de algumas das IES da amostra, de que o aluno é simplesmente um cliente. Tal interpretação tem gerado um processo que mina e deteriora, de maneira clara e objetiva, a autoridade representada pela figura docente, tornando-a vulnerável e potencialmente exposta a situações de assédio moral.

Quadro 5

Situações caracterizadas como assédio moral

\begin{tabular}{|c|l|l|}
\hline Situação & \multicolumn{1}{|c|}{ Assediador } & \multicolumn{1}{c|}{ O que ocorreu } \\
\hline 1 & Diretor & Mentiras, perseguição, difamação \\
\hline 2 & Orientador & Chantagem, ameaças, perseguição \\
\hline 3 & Alunos & Difamação, desqualificação \\
\hline
\end{tabular}


Cont. Quadro 5

\begin{tabular}{|c|c|c|}
\hline Situação & Assediador & O que ocorreu \\
\hline 4 & Coordenador & Acusações sem fundamento \\
\hline 5 & Orientador & Desrespeito, ironia, agressividade \\
\hline 6 & Coordenador & Desrespeito, advertências sem fundamento \\
\hline 7 & Coordenador & Manipulação de dados \\
\hline 8 & Colegas & Isolamento, condutas hostis \\
\hline 9 & Instituição & Adoção de normas antiéticas \\
\hline 10 & Coordenador & Desrespeito, agressividade, ameaças \\
\hline 11 & Diretor & Desrespeito, pressão para adoção de conduta ilegal \\
\hline 12 & Coordenador & Desrespeito, ameaças \\
\hline 10 & Diretor & Desrespeito, isolamento, recusa de comunicação \\
\hline 13 & Coordenador & Desrespeito, humilhação \\
\hline 14 & Aluno & Desrespeito, difamação \\
\hline 15 & Coordenador & Recusa de comunicação, boicote de ideias \\
\hline 16 & Colegas & Isolamento, discriminação \\
\hline 17 & Reitor & Desrespeito, discriminação \\
\hline 18 & Ex-aluno & Difamação, mentiras, fofoca \\
\hline
\end{tabular}

Fonte: Dados da pesquisa, 2012.

Ao identificar a figura do gestor como não sendo o único, mas um dos principais perpetradores nos processos de assédio moral (HIRIGOYEN, 2002a; 2002b) - aspecto corroborado nesta pesquisa - faz-se necessário enfatizar que aqueles que ocupam posições de liderança nas organizações devem aderir aos princípios que as guiam para poder exercer seu papel de maneira eficiente e eficaz (BARRETO, 2005). Assim, seja pela aquisição ou pela manutenção de privilégios referentes ao cargo (ou meramente pelo emprego em si), o assediador tem seu portfólio de táticas respaldado, aceito e até incentivado pelas instituições que, salvo algumas exceções identificadas na pesquisa, têm incorporados em sua cultura o desrespeito, a humilhação, a falta de profissionalismo ou o descaso com o trabalho desenvolvido pelo docente.

Nesse sentido, deve-se ressaltar que, se as práticas de assédio moral podem ser consideradas traços perversos comuns no âmbito educacional (sustentadas pela cultura em algumas instituições), os gestores, os orientadores e os alunos encontrarão um terreno fértil para a prática de toda sorte de atrocidades, desde as mais sutis até as mais explícitas.

No que se refere à variedade de práticas utilizadas pelos assediadores, além de demonstrarem o quão perversos podem ser os processos de assédio, chamam atenção pela sua sutileza e sinuosidade, o isolamento, a ironia, a recusa de comunicação, o boicote de ideias, as chantagens e as ameaças veladas. A sutileza na 
ação dos agressores, normalmente, faz com que o assédio seja percebido, muitas vezes, apenas pela vítima, ocorrendo com mais frequência em funções mais flexíveis e subjetivas (HIRIGOYEN, 2002b), representadas por funções administrativas e também pela ação docente, como foi possível identificar nos dados apresentados pelos entrevistados.

Assim, as condições organizacionais favoráveis à ocorrência de assédio moral percebidas por docentes que atuam em IES privadas, em cursos de administração de empresas pertinentes à amostra, demonstram estar relacionadas à complexidade e à multiplicidade das atividades desenvolvidas pelos professores. Do mesmo modo, têm relação com a frequência e a variedade das interações profissionais destes, com a conduta adotada por algumas instituições no sentido de tratar o aluno como mero cliente, com a naturalização das práticas de assédio moral na cultura das IES e, também, com a fragilidade ou inexistência de normas e de processos referentes à prevenção e à abordagem desse fenômeno.

Quanto aos impactos decorrentes da vivência de processos de assédio moral, foram abordados elementos pertinentes à vida pessoal, à carreira e ao ambiente de trabalho. No que se refere às consequências na vida pessoal, os entrevistados mencionaram impactos negativos sob os pontos de vista financeiro e físico, bem como impactos positivos referentes a processos de aprendizagem, amadurecimento, reflexão e mudanças decorrentes das situações de assédio moral vivenciadas. Com relação aos efeitos nocivos das situações de assédio nas suas carreiras, alguns entrevistados não identificaram maiores impactos. Outros mencionaram a perda do interesse em constituir carreira na instituição onde a situação de assédio ocorreu, desejo de mudar de área de atuação - citado em casos onde foram evidenciados conflitos com o superior hierárquico e desencanto com a carreira acadêmica. Quanto ao impacto no ambiente de trabalho, foram mencionadas questões referentes à credibilidade do trabalho desenvolvido pelo docente, notadamente, em situações nas quais o docente foi vítima de fofocas e de difamação.

Também foi observado que as próprias IES não ficaram isentas dos efeitos nocivos das situações de assédio moral. Isso é representado pela perda de talentos ou pelo arrefecimento do desejo de continuar a lecionar em determinada IES. Esses aspectos (somados às mudanças de áreas mencionadas por alguns entrevistados) também podem interferir negativamente na imagem da IES, tanto na ótica dos outros profissionais que nela atuam, quanto para novos profissionais, que podem se desinteressar por trabalhar em uma IES onde o ambiente de trabalho é reconhecido como tóxico.

Sem deixar de considerar as diferenças e as particularidades nos relatos dos entrevistados, merece destaque a força destrutiva dos processos de assédio e o quanto essa força reverbera na vida de quem foi vítima. Sentir raiva, sentir medo, culpar-se por um erro não cometido, ser coagido ou forçado a pedir demissão, ter depressão ou um princípio de AVC (acidente vascular cerebral) constituem reações sérias e, em alguns casos, irreversíveis na vida de alguém, chamando atenção para o fato de que os processos de assédio moral precisam ser reconhecidos, tratados e, sobretudo, prevenidos. Ainda que tenham sido apresentadas consequências aparentemente positivas, melhor seria se, nesse caso, estas não existissem, pois a sua inexistência levaria a pressupor a não ocorrência do mal que as originou.

A análise dos dados que emergiram dos processos trabalhistas e das entrevistas trouxeram à tona problemas para todas as instâncias envolvidas que continuarão ocorrendo, caso a reprodução desse modelo se perpetue. Considerando-se os outputs desse processo - a) a fragilização cada vez maior dos propósitos educacionais das IES em função das preocupações com lucro e imagem; e b) o aviltamento das condições de trabalho do professor, principal agente no processo educacional, sob o ponto de vista humano e profissional -; entendese como necessária a proposição de ações pertinentes à prevenção e ao tratamento desse fenômeno que tem características potencialmente tão devastadoras.

A prevenção da ocorrência de assédio moral no ambiente acadêmico também foi abordada pelos docentes entrevistados. Foram mencionados elementos referentes à transparência da gestão, à existência e à clareza de políticas/processos. Foi recorrente ainda a menção à construção de uma cultura favorável, bem como à disponibilização de canais de comunicação e/ou de denúncia das situações de assédio. Segundo os dados 
analisados, nos ambientes onde existe uma cultura e um modelo de gestão que estimulem e propiciem o diálogo e a adoção de condutas transparentes, pouco ou nenhum espaço haverá para que ocorram práticas perversas, como as identificadas neste artigo.

\section{Considerações Finais}

Este estudo visou identificar e analisar as condições organizacionais que favorecem a ocorrência do assédio moral e o modo como este ocorre na perspectiva de professores que atuam em cursos de administração de empresas de IES privadas na cidade de São Paulo. Foi evidenciado que o assédio moral percebido pelos docentes ocorre em diversas instâncias de sua atuação profissional, motivado por questões pessoais e organizacionais, apresentando múltiplas faces, que se manifestam nas mais diferentes formas de violência.

Foi possível identificar que a frequência de interações pessoais pertinentes ao exercício do papel docente constitui um dos fatores que o expõe a situações de assédio. No entanto, outros elementos sinalizaram que a multiplicidade de papéis exercidos por docentes também pode representar elemento determinante na exposição do professor ao assédio. Nesse sentido, deve ser considerado que esse fenômeno não somente ocorre no exercício do papel de docente propriamente dito. Também pôde ser evidenciado nas relações entre orientandos e orientadores, em instâncias relacionadas ao exercício do papel de pesquisador, no relacionamento com colegas de trabalhos, na interação com superiores hierárquicos e até mesmo na relação com ex-alunos.

A existência de relações de poder entre assediador e assediado demonstra ser consenso nas abordagens sobre a dinâmica das situações de assédio moral, sendo importante destacar que esse poder nem sempre está diretamente relacionado à figura que representa o poder hierárquico.

Esse cenário, além de reforçar a fragilidade e o desrespeito pelo papel e a imagem do docente, afeta definitivamente o bom exercício de sua função. Além disso, revela um contexto profissional cujos conflitos são vividos pelos professores, muitas vezes, de maneira solitária e sem eco junto às lideranças hierárquicas, que são, em muitos casos, os principais deflagradores das situações de assédio moral. Não é possível deixar de considerar que os efeitos nocivos de processos dessa natureza, além de atingir diretamente os docentes, têm sua abrangência potencializada à medida que interferem diretamente no processo de ensinoaprendizagem e na qualidade de ensino.

Os aspectos culturais das IES se mostraram relevantes para compreender as situações de assédio analisadas, em que foi possível verificar contextos de permissividade e/ou conivência. A naturalização dos processos de assédio é preocupante, não somente porque dificulta as ações relacionadas à prevenção e ao combate, mas por reforçar a estigmatizarão da vítima e, consequentemente, seu sofrimento, além de refletir um cenário em que situações de profunda degradação das condições de trabalho e dos relacionamentos interpessoais são interpretadas como normais.

Se as práticas de assédio moral são consideradas traços perversos comuns no âmbito educacional e sustentadas pela cultura da instituição, gestores, orientadores e alunos encontrarão condições férteis para a prática de toda sorte de atrocidades. É importante considerar que a naturalização das ocorrências de assédio moral e quaisquer outras formas de violência (situações que, embora não sejam configuradas como assédio moral, exigem atenção por também serem graves) trazem consigo a banalização daquilo que não é profissional, do que não deveria ser tolerado, daquilo que é, no mais das vezes, desumano, e que pode ter consequências gravíssimas, não apenas para o docente diretamente envolvido. Essa dinâmica é perversa e deve ser combatida: a naturalização torna o ambiente cada vez mais hostil e suas consequências podem ir muito além do aspecto temporal imediato. 
As eventuais reações contrárias ou a indiferença das IES às situações de assédio são elementos cruciais na análise desse fenômeno no ambiente acadêmico. Assim, se a possibilidade de ocorrência do assédio moral sequer é considerada no que se refere ao estabelecimento de normas, procedimentos, ações preventivas e tratamento dos casos, o ambiente tornar-se-á altamente propício a essa forma de violência. A multiplicidade de papéis exercidos pelo docente e a frequência de suas interações pessoais (inerente ao exercício de suas funções) acabam ampliando as chances de que o assédio moral ocorra.

Em que pese aos aspectos idiossincráticos pertinentes a cada uma das situações de assédio analisadas (cujo perfil psicológico e/ou momento de vida do assediador e do assediado exerceram um papel de suma importância na compreensão dos processos de assédio moral percebidos pelo docente), o contexto em cujas situações ocorreram também deve ser considerado. Esse mesmo contexto poderá mitigar, neutralizar, reforçar, induzir ou repelir ocorrências de assédio.

A falta de canais de comunicação confiáveis, de normas claras e transparentes, de cuidados no processo de contratação e de acompanhamento daqueles que exercem papéis de liderança, aliados à inexistência de uma atuação efetiva da área de gestão de pessoas (ou recursos humanos) em algumas IES, não somente demonstram a naturalização dos processos perversos, mas também podem retroalimentar um círculo vicioso, que reforça a estigmatização e a solidão de quem sofre assédio.

Cabe destacar que os fenômenos que ocorrem no interior das organizações, incluído o assédio moral, guardam relação direta com o contexto sociocultural, político e histórico em que estas estão inseridas. No caso das IES, foram identificados aspectos relacionados à excessiva competição e à velocidade demandadas no ambiente onde estão inseridas. Tanto a opção de tratar o aluno como cliente (em detrimento do processo educativo e do trabalho desenvolvido pelo professor) como a competitividade verificada entre os docentes nas próprias IES são elementos que fomentam e, em alguns casos, subjazem às práticas de assédio moral, seja entre colegas docentes, seja na relação com o aluno, seja com a liderança hierárquica.

O medo de perder o emprego, aliado (ou não) ao forte desejo de evitar conflitos estão entre os sentimentos que respaldam a ocorrência do assédio moral sofrido por professores, agindo como um motor que mantém o ritmo das práticas de assédio, alimentadas pela cumplicidade do silencia individual e/ou coletivo. Nesse sentido, é fundamental apontar a importância de uma postura ativa por parte dos docentes quanto ao seu trabalho e a sua carreira que amplie seu olhar para um cenário, muitas vezes, contraditório, árido e indigesto. Um cenário que, contudo, não pode ser dissociado de sua opção de vida e que, no dia a dia, demanda serem tomadas posições, principalmente, diante de situações indesejáveis ou mesmo de conflito, conforme as reveladas neste estudo.

A adoção de uma postura ativa precede a compreensão / prescinde da compreensão de que os professores nem sempre são apenas as vítimas nos processos de assédio. Eventualmente, outras posturas e outros papéis devem ser assumidos, o que inclui a busca pelo diálogo, o questionamento e, em alguns casos, até mesmo uma atitude menos transigente. Desse modo, se não existir um movimento de ação e/ou reação por parte dos professores, haverá o favorecimento da manipulação, da omissão e do autoritarismo nas questões referentes ao magistério, tornando o dia a dia mais penoso e os nós mais difíceis de serem desatados.

Ainda que a ocorrência de assédio moral de docentes não constitua privilégio de quem atua especificamente nos cursos de administração de empresas, seja na graduação, lato ou stricto sensu, cumpre destacar que nessas instâncias os alunos, em tese, aprendem (ou deveriam aprender) como administrar. É, no mínimo, paradoxal constatar nessas mesmas instâncias, segundo dados da pesquisa, a inexistência ou fragilidade de normas e processos, além de elementos rudimentares relacionados à comunicação e à gestão de pessoas. Isso indica que há muitas oportunidades, além da necessidade de aperfeiçoamentos. Segundo um jargão próprio do universo acadêmico: "uma lição de casa" a ser cumprida.

A prevenção e o combate ao assédio moral no ambiente de trabalho devem incluir elementos que contribuam para sensibilizar os profissionais envolvidos, independentemente de posição hierárquica. Nesse sentido, é 
fundamental levar em conta a necessidade de mudanças na forma de organizar e administrar pessoas, o que no caso das IES envolve: a) uma atuação efetiva da área de gestão de pessoas e/ou da mais alta esfera hierárquica visando ao estabelecimento de canais fluidos e confiáveis de comunicação, informação e diálogo para docentes, orientandos e alunos, bem como no que se refere à formação e ao acompanhamento constantes daqueles que, além das funções docentes, também exercem papéis de lideranças; b) estabelecimento de regras, políticas e/ou processos claros e amplamente difundidos sobre aspectos que regem a vida do profissional na instituição, que vão desde elementos relacionados a questões burocráticas àqueles relativos a questões comportamentais (incluindo normas e valores adotados pela IES), os quais devem expressar intolerância a qualquer forma de atentado à segurança física, mental e/ou dignidade do profissional no exercício de suas funções.

No âmbito externo às IES, deve-se considerar a atuação dos sindicatos e do Poder Legislativo, os quais, sem dúvida, também têm um destacado papel nesse contexto. No caso dos sindicatos, esse papel é representado por uma ação vigilante e uma postura ativa no que se refere a todo e qualquer aspecto da vida laboral do professor, seja no que se refere ao descumprimento de questões legais pelas IES, seja no que se refere a elementos relacionados ao seu bem-estar físico e mental, que incluem a violência explícita ou sutil que faz parte dos processos de assédio moral. No caso do Poder Legislativo, por uma atuação incisiva e incansável, de forma que seja criada, no curto prazo, uma legislação específica sobre o assédio moral em nível federal, a exemplo do que ocorre em países como França, Suíça e Bélgica, entre outros.

Tanto no nível pessoal quanto coletivo, é fundamental e necessária a adoção de ações múltiplas e não isoladas, pois é assim que se pode conseguir eco e visibilidade à prevenção e ao combate a um mal que não acaba em si, mas que reverbera de maneira tão profunda quanto abrangente na vida de quem o sofre, afetando sobremaneira seu entorno e que, no caso de envolver a ação educacional, como já observamos, tem sua ação estendida no que diz respeito ao aspecto temporal. A partir de ações pontuais, assertivas e insistentes será possível promover as mudanças necessárias no sentido de que o fenômeno do assédio moral possa ser reconhecido e entendido em toda sua complexidade e gravidade.

As próprias IES têm uma grande contribuição a dar, seja promovendo debates, seja produzindo e divulgando pesquisas sobre o problema (que além de as atingir numa primeira instância, afeta também a sociedade; visto a partir de uma análise mais abrangente). Assim, dentre as contribuições deste estudo, destaca-se a importância de uma olhar mais atento sobre o assédio moral sofrido pelos professores nos diferentes papéis que lhe são atualmente impostos pelas IES. Isso possibilita abrir espaços de reflexão que resultem em ações profícuas e transformadores desse cenário que diz respeito não apenas ao professor, mas igualmente às gerações formadas por este profissional, da mesma forma que aos valores e condutas adotados por essas gerações.

Além dos elementos relacionados à compreensão do assédio moral no ambiente acadêmico, esta pesquisa evidenciou a necessidade de prevenção e enfrentamento do problema. Também apontou outras lacunas quanto ao estabelecimento de um ambiente de trabalho mais saudável, justo e digno para os docentes que atuam no nível superior e que se veem a mercê de gestores despreparados, ineficientes e ineficazes num ambiente desprovido de normatização. Se levarmos em consideração os casos observados neste estudo, tratase de ambientes que não disponibilizam condições mínimas para o desenvolvimento do trabalho docente.

\section{Referências}

ABRAMOVAY, M.; RUA, M. G. Violência nas escolas. Brasília: Unesco, 2002.

BARDIN, L. Análise de conteúdo. Lisboa: Edições 70, 2006. 
BARRETO, M. Assédio moral: a violência sutil. 2005. 188f. Tese (Doutorado em Psicologia Social) - Pontifícia Universidade Católica, São Paulo, São Paulo. Análise epidemiológica e psicossocial do trabalho no Brasil. Tese (Doutorado em Psicologia Social) - Pontifícia Universidade Católica, São Paulo, 2005.

BAUER, M. W.; AARTS, B. A construção do corpus: um princípio para a coleta de dados qualitativos. In: GASKELL, G. (Eds.). Pesquisa qualitativa com texto, imagem e som: um manual prático. Petrópolis: Vozes, 2002. 39-63 p.

BIRMAN, J. O assédio na atualidade e seus jogos de verdade. Revista do Departamento de Psicologia da UFF, Niterói, v. 17, n. 1, p. 29-44, jan./jun. 2005.

BRADASCHIA, C. A. Assédio moral no trabalho: a sistematização dos estudos sobre um campo em construção. 2007. 230f. Dissertação (Mestrado em Administração de Empresas) - Fundação Getulio Vargas, São Paulo, 2007.

CARAN, V. C. S. Riscos psicossociais e assédio moral no ambiente acadêmico. 2007. 188f. Dissertação (Mestrado em Enfermagem) - Escola de Enfermagem de Ribeirão Preto, Universidade de São Paulo, Ribeirão Preto, 2007.

CASSITTO, M. G. et al. Raising awareness of psychological harassment at work. Protecting Workers' Health Series, n. 4, p. 15, 2012. Disponível em: 〈http://www.who.int/occupational_health/publications/en/pwh4e.pdf〉. Acesso em: 22 set. 2012.

CHARLOT, B. A violência na escola: como os sociólogos franceses abordam essa questão. Sociologias, Porto Alegre, n. 8, p. 432-443, jul./dez. 2002.

DENZIN, N. K.; LINCOLN, Y. S. A disciplina e a prática da pesquisa qualitativa. In: planejamento da pesquisa qualitativa: teorias e abordagens. Porto Alegre: Artmed, 2006. 15-41 p.

EINARSEN, S. et al. Bullying and harassment in the workplace - developments in theory, research and practice. Florida: Taylor \& Francis Group, 2011.

FRANCO, M. L. P. B. Análise de conteúdo. Brasília: Liber Livro Editora, 2008.

FREITAS, M. E. Assédio moral e assédio sexual: faces do poder perverso nas organizações. RAE - Revista de Administração de Empresas, São Paulo, v. 41, n. 2, p. 8-19, abr./jun. 2001.

Disponível

. Quem paga a conta do assédio moral no trabalho? RAE Eletrônica, São Paulo, v. 6, n. 1, p. 1-7, jan./jun. 2007.

http://rae.fgv.br/busca?busca=Quem+paga+a+conta+do+ass\%C3\%A9dio\&autor=\&pc=\&ano\%5Bmin $\% 5 \mathrm{D}=\& a n o \% 5 \mathrm{~B}$

$\max \% 5 \mathrm{D}=\&$ revista=All\&edicao=All. Acesso em 12 set. 2011.

; HELOANI, R.; BARRETO, M. Assédio moral no trabalho. São Paulo: Cengage Learning, 2008.

GLINA, D. M. R.; SOBOLL, L. A. Intervenções em assédio moral no trabalho: uma revisão da literatura. Revista Brasileira de Saúde Ocupacional, São Paulo, v. 37, n. 126, p. 269-283, jul./dez. 2012.

GODOY, A. S. Pesquisa qualitativa - tipos fundamentais. RAE - Revista de Administração de Empresas, São Paulo, v. 35, n. 2, p. 57-63, maio/jun. 1995.

HELOANI, J. R. Contribuições da psicologia do trabalho em casos de assédio moral. In: SOBOLL, L. A. (Org.). Violência psicológica no trabalho e assédio moral: pesquisas brasileiras. São Paulo: Casa do Psicólogo, 2008. 95-104 p.

HIRIGOYEN, M. F. Assédio moral: a violência perversa no cotidiano. Rio de Janeiro: Bertrand, 2002a.

. Mal-estar no trabalho: redefinindo o assédio moral. Rio de Janeiro: Bertrand, 2002b. 
LELIS, I. O trabalho docente na escola de massa: desafios e perspectivas. Sociologias, Porto Alegre, v. 14, n. 29, p. 152-174, jan./abr. 2012.

MEURER, B.; STREY, M. N. Problematizando as práticas psicológicas no modo de compreender o fenômeno assédio moral. Revista Psicologia: Ciência e Profissão, Brasília, v. 32, n. 2, p. 452-471, 2012.

MINAYO, M. C. S. O desafio da pesquisa social. In: DESLANDES, S. F.; GOMES, R.; MINAYO, M. C. S. Pesquisa social: teoria, método e criatividade. Petrópolis: Vozes, 2010. 9-29 p.

MINTO, L. W. As reformas do ensino superior no Brasil: o público e o privado em questão. Campinas: Autores Associados, 2006.

OLIVEIRA, L. R. C. Existe violência sem agressão moral? Revista Brasileira de Ciências Sociais, São Paulo, v. 23, n. 67, p. 135-146, jun. 2008.

PAULA, A. P. P.; RODRIGUES, M. A. Pedagogia crítica no ensino da administração: desafios e possibilidades. RAE Revista de Administração de Empresas, São Paulo, v. 46, n. Edição Especial, p. 10-22, nov./dez. 2006.

PIRES, A. P. Amostragem e pesquisa qualitativa: ensaio teórico e metodológico. In: POUPART, J. et al. A pesquisa qualitativa: enfoques epistemológicos e metodológicos. Petrópolis: Vozes, 2010. 154-211 p.

PITA, M. Stress laboral, assédio moral e burnout marcam produtivismo. Revista Adusp, São Paulo, n. 48, p. 14-21, set. 2010 .

SCHWANDT, T. A. Três posturas epistemológicas para a investigação qualitativa: interpretativismo, hermenêutica e construcionismo social. In: DENZIN, N. K.; LINCOLN, Y. S. O planejamento da pesquisa qualitativa: teorias e abordagens. Porto Alegre: Artmed, 2006. 193-217 p.

SESSO, P. R. Assédio moral no trabalho. 2005. 127f. Monografia (Direito do Trabalho) - Pontifícia Universidade Católica, São Paulo, 2005.

SIERRA, F. Función y sentido de la entrevista cualitativa em investigación social. In: CÁCERES, L. J. G. (Coord.). Técnicas de investigación em sociedad, cultura y comunicación. México: Prentice Hall, 1998.

SIROTA, A. Humilhação social: uma reflexão sob o ponto de vista psicanalítico. Estudos de Psicologia, Campinas, v. 25, n. 4, p. 557-565, out./dez. 2008.

SOARES, A. As origens do conceito de assédio moral no trabalho. Revista Brasileira de Saúde Ocupacional, São Paulo, v. 37, n. 126, p. 284-286, jul./dez. 2012.

SOBOLL, L. A. (Org.). Violência psicológica no trabalho e assédio moral: pesquisas brasileiras. São Paulo: Casa do Psicólogo, 2008.

SPOSITO, M. P. Um breve balanço da pesquisa sobre violência escolar no Brasil. Educação e Pesquisa, São Paulo, v. 27, n. 1, p. 87-103, jan./jun. 2001.

VALLES, M. S. Técnicas qualitativas de investigación social: reflexión metodológica y práctica profesional. Madrid: Sintesis, 1997.

ZALUAR, A.; LEAL, M. C. Violência extra e intramuros. Revista Brasileira de Ciências Sociais, São Paulo, v. 16, n. 45, p. 145-164, fev. 2001. 